\title{
Laboratory Test Results Portion or Totality
}

National Cancer Institute

\section{Source}

National Cancer Institute. Laboratory Test Results Portion or Totality. NCI Thesaurus. Code C119850.

A qualifier for the arrangement or apportioning of an entity within a body part, region or organ for a laboratory test. 